\title{
The NAME trial: a direct comparison of classical oral Navelbine versus Metronomic Navelbine in metastatic breast cancer
} \author{
Torbøl Brixen ${ }^{5}$, Mie Grunnet ${ }^{6}$, Lars Stenbygaard ${ }^{7}$, Bjørnar Gilje ${ }^{8}$, Hella Dan ${ }^{9}$, Vesna \\ Glavicic $^{10}$, Erik Hugger Jacobsen ${ }^{11}$, Anne Sofie Brems-Eskildsen ${ }^{1}$, Helle Lemvig Kruse ${ }^{1}$, Trine \\ Dongsgaard $^{12}$, Jeppe Neimann ${ }^{1}$ \& Jürgen Geisler*,13,14 (iD \\ ${ }^{1}$ Department of Oncology, Aarhus University Hospital, 8200 Aarhus C, Denmark \\ ${ }^{2}$ Department of Oncology, Regionshospitalet Herning, 7400 Herning, Denmark \\ ${ }^{3}$ Department of Oncology, Odense University Hospital, 5000 Odense, Denmark \\ ${ }^{4}$ Department of Oncology, Sønderborg Sygehus, 6400 Sønderborg, Denmark \\ ${ }^{5}$ Department of Oncology, Herlev Hospital, 2730 Herlev, Denmark \\ ${ }^{6}$ Department of Oncology, Rigshospitalet, 2100 Copenhagen, Denmark \\ ${ }^{7}$ Department of Oncology, Aalborg Sygehus Syd, 9100 Aalborg, Denmark \\ ${ }^{8}$ Department of Hematology \& Oncology, Stavanger University Hospital, 4011 Stavanger, Norway \\ ${ }^{9}$ Department of Oncology, Hilleroed Hospital, 3400 Hilleroed, Denmark \\ ${ }^{10}$ Department of Oncology, Naestved, 4700 Naestved, Denmark \\ ${ }^{11}$ Department of Oncology, Sydvestjysk Sygehus Esbjerg, 6700 Esbjerg, Denmark \\ ${ }^{12}$ Department of Oncology, Regionshospitalet Herning, 7400 Herning, Denmark \\ ${ }^{13}$ Department of Oncology, Akershus University Hospital, 1478 Lørenskog, Norway \\ ${ }^{14}$ Institute of Clinical Medicine, University of Oslo, 0372 Oslo, Norway \\ *Author for correspondence: Tel.: +47 67963800; Fax: +47 67963820; juergen.geisler@medisin.uio.no
}

Sven Tyge Langkjer ${ }^{1}$, Julia Kenholm², Jeanette Dupont Jensen ${ }^{3}$, Kim Wedervang ${ }^{4}$, Annette

Chemotherapy for metastatic breast cancer (MBC) is in general given in cycles of maximum tolerated doses to potentially maximize the therapeutic outcome. However, when compared with targeted therapies for $M B C$, conventional and dose intensified chemotherapy has caused only modest survival benefits during the recent decades, often compromising the quality of life considerably. Navelbine is an antineoplastic agent that has shown efficacy in the treatment of a variety of cancer types, including breast cancer. Early clinical trials involving both breast cancer and lung cancer patients suggest that metronomic dosing of Navelbine might be at least as effective as classical administration (once weekly, etc.). The NAME trial compares these two strategies of Navelbine administration in MBC patients.

First draft submitted: 5 March 2019; Accepted for publication: 29 May 2019; Published online: 19 June 2019

Keywords: breast cancer $\bullet$ chemotherapy $\bullet$ metronomic $\bullet$ NAME $\bullet$ Navelbine $\bullet$ Phase II trial $\bullet$ vinorelbine

Navelbine (vinorelbine; Pierre Fabre Pharmaceuticals, Castres, France) is an antineoplastic agent that has shown efficacy in the treatment of a variety of solid tumors, including breast cancer [1-3]. Although the drug may be given intravenously, administration by the oral route has been increasingly established for breast cancer patients during the last decade. Results from preclinical studies suggest that the administration of small, frequent doses of chemotherapy (metronomic chemotherapy $[\mathrm{mCHT}]$ ) may have an effect on endothelial cells in the tumor vasculature [4-6] in addition to the direct effects on tumor cells. Based on the available evidence, giving smaller but more frequent doses of drugs such as vinorelbine should cause a higher dose intensity without corresponding increases in side effects. However, whether anticancer treatment following the metronomic principle is superior to conventional drug dosing, has not yet been validated in larger clinical trials. The NAME study, presented here, has the potential to determine this and thus benefit patients suffering from metastatic breast cancer (MBC).

Breast cancer is among the world's most common cancer types in women [7]. In Denmark and Norway, approximately 4800 and 3600 new breast cancer cases are diagnosed every year, respectively. MBC is currently incurable and cytotoxic therapy prolongs survival only modestly [8]. Very few cytotoxic regimens have shown a clear

Future $\because$ Medicine 


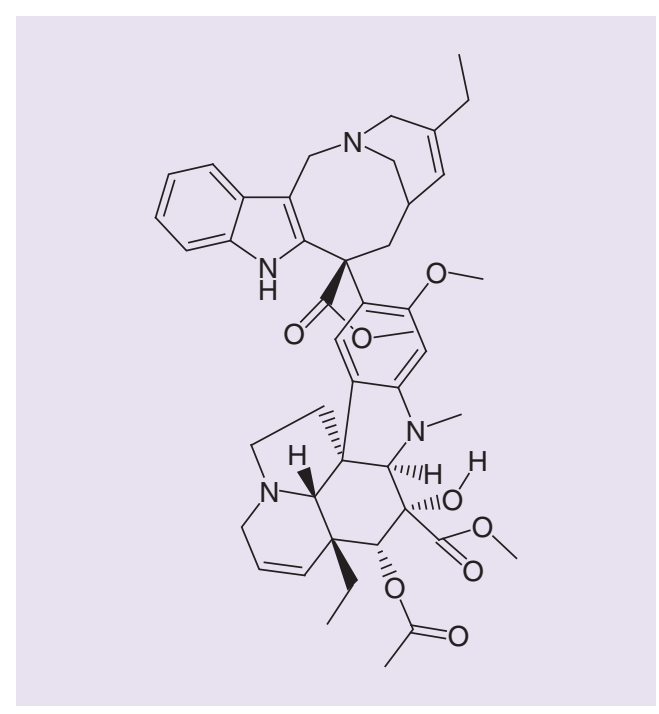

Figure 1. Navelbine (vinorelbine) - chemical structure.

survival benefit. The main goal for treatment of patients with $\mathrm{MBC}$ is to relieve symptoms and balance prolonging survival with quality of life. The benefits and disadvantages of chemotherapy need to be carefully considered. In light of this, MBC patients with hormone-sensitive diseases, often are treated with antihormonal regimens (antiestrogens, aromatase inhibitors, etc.) for longer time periods. However, endocrine resistance inevitably occurs and standard chemotherapy regimens will therefore be offered to the majority of patients.

Some of the most established types of chemotherapy for the treatment of MBC are anthracyclines and taxanes. These drugs are unfortunately quite toxic and many patients may have used these drugs in the adjuvant setting, somewhat limiting their efficacy in MBC. Thus, there is a great need for other effective chemotherapy regimens with acceptable side-effect profiles that may be used in the advanced situation of the breast cancer disease. Systematic reviews of available chemotherapeutic treatment options for $\mathrm{MBC}$ following progression on anthracyclines and taxanes recommend drugs like capecitabine or vinorelbine in this setting [9]. Eribulin has recently been shown to have some activity in this setting as well $[10,11]$.

In HER-2 negative MBC, there is currently no single, optimal first-line chemotherapy or following line of chemotherapy and the clinician's choice of therapy will be made based on factors like prior therapy lines, time after termination of adjuvant therapy, toxicity, performance status, comorbidity, age and the preferences of the individual patient. In addition, an optimal sequence of chemotherapeutic options has not been established thus far.

The preferable side-effect profile of vinorelbine monotherapy and its proven capacity to stabilize MBC while preserving an acceptable quality of life makes this drug a good candidate for further studies in MBC aiming to improve outcome and side effects during treatment [12]. Its oral administration makes the drug a patientfriendly treatment option requiring less frequent visits to the cancer ward, compared with standard intravenous chemotherapies.

Conventional chemotherapy is often given intravenously every 3 weeks (e.g., anthracyclines, taxanes) or weekly (taxanes). Especially the three-weekly regimens are causing considerable side effects and complications (infections, bone marrow suppression, etc.) and may lead to hospitalization and periods without treatment to allow the patients to recover. Long treatment intervals and also necessary treatment holidays may allow some tumor cell clones to regrow or possibly adapt to therapy.

A novel strategy to avoid the extreme side effects of established chemotherapy regimens is the so-called 'metronomic approach'. Metronomic dosing entails frequent but small doses of chemotherapy without major treatmentfree intervals. mCHT is increasingly believed to interfere with the vascular endothelial cells in the tumors and thereby influence tumor angiogenesis and to have stimulatory effects on the immune system [13-19]. mCHT is currently being tested in clinical trials for a variety of human cancer types, however, optimal drugs and dose schedules have yet to be established.

\section{Navelbine}

Navelbine (vinorelbine) belongs to the group of vinca alkaloids (Figure 1), blocking cell division in the G2/M-phase 
of the cell cycle by inhibiting the assembly of microtubules, which are necessary for cell division. Vinorelbine is considered less toxic compared with taxanes, anthracyclines and other vinca alkaloids. The drug is available for both oral and intravenous administration.

\section{Vinorelbine as intravenous therapy}

A Phase I study reported a maximum tolerable dose of $35 \mathrm{mg} / \mathrm{m}^{2}$ weekly, when vinorelbine was administered as monotherapy [20]. Granulocytopenia was the most significanr dose-limiting factor. The same report recommended the $30 \mathrm{mg} / \mathrm{m}^{2}$ dose for Phase II trials. A Phase I-II study showed that the maximum tolerable dose was $40 \mathrm{mg} / \mathrm{m}^{2}$ when given on day 1 and 8 every 3 weeks. Thus, the dose for subsequent studies was set to $35 \mathrm{mg} / \mathrm{m}^{2}$ [21]. Vinorelbine is commonly used in doses of $30 \mathrm{mg} / \mathrm{m}^{2}$ weekly, causing clinical response rates between 40 and $60 \%$ as first-line therapy in MBC [22-26]. A study from Denmark confirmed a clinical benefit rate of $38 \%$ with an intentionto-treat response rate of $12 \%$ [21]. Vinorelbine given in combination with other chemotherapeutics has shown high response rates of $62-65 \%$ and efficacy at the same level as other combinations. A prospective randomized Phase III trial compared vinorelbine in combination with epirubicin to epirubicin alone. The combination resulted in significantly higher response rates (50 vs $42 \%$ ). The drug doses in this study were $90 \mathrm{mg} / \mathrm{m}^{2}$ epirubicin and vinorelbine $25 \mathrm{mg} / \mathrm{m}^{2}$ on days 1 and 8 [27].

The HERNATA-trial tested vinorelbine in tandem with trastuzumab (Herceptin) in HER-2 positive breast cancer patients and compared this combination with a combination of docetaxel and trastuzumab [28]. While the response rates were very similar between the two arms, the combination with vinorelbine caused significantly fewer side effects and has become the first-line therapy for HER-2 positive MBC in Denmark as a result of this study.

\section{Vinorelbine as oral therapy}

An oral formulation of vinorelbine has been developed and is now widely established in clinical practice worldwide. It consists of a soft gelatin capsule filled with the drug. Factors affecting the bioavailability of the oral administration of vinorelbine include solubility, absorption through the mucosa of the gastrointestinal tract, the first-pass metabolism in mucosa and the liver and the distribution of the drug in various tissues. The bioavailability of oral vinorelbine is $43 \%(+/-14 \%)$ and there is bioequivalence of $80 \mathrm{mg} / \mathrm{m}^{2}$ orally and $30 \mathrm{mg} / \mathrm{m}^{2}$ intravenously as well as $60 \mathrm{mg} / \mathrm{m}^{2}$ orally and $25 \mathrm{mg} / \mathrm{m}^{2}$ intravenously [29]. Comparative studies of intravenous administration and oral treatment with vinorelbine have been conducted in non-small-cell lung cancer patients. In a Phase II study [30], 114 patients with metastatic or advanced disease were randomized to either oral vinorelbine $\left(60 \mathrm{mg} / \mathrm{m}^{2}\right.$ weekly, with the option of a dose-escalation to $\left.80 \mathrm{mg} / \mathrm{m}^{2}\right)$ or intravenous vinorelbine $\left(30 \mathrm{mg} / \mathrm{m}^{2}\right.$ weekly) monotherapy. The authors reported a response rate of 14 and $21 \%$, respectively and a median survival of 9.3 and 7.9 months, respectively. The 1-year survival rate was 41 and 29\%, respectively. The differences, however, were not statistically significant. In the aforementioned study and an analysis of four other Phase II studies, toxicity was compared between oral and intravenous administration of vinorelbine. Taken together, the evidence suggests a comparable toxicity, but that oral administration is accompanied by a predominance of gastrointestinal side effects. Grade III-IV nausea and vomiting occurred in 11 and $8 \%$ of the patients when treatment was given orally while the corresponding toxicity was 0 and $3 \%$ when given intravenously. Neither trial prescribed prophylactic anti-emetics to its subjects. The toxicity was clearly dose-related as expected. A dose increase from 60 to $80 \mathrm{mg} / \mathrm{m}^{2}$ was recommended only for patients with good tolerability at the $60 \mathrm{mg}$ dose. Freyer and colleagues concurred in their breast cancer study where vinorelbine was administered orally as first-line treatment of MBC. Vinorelbine could be given as $60 \mathrm{mg} / \mathrm{m}^{2}$ weekly and increased to $80 \mathrm{mg} / \mathrm{m}^{2}$ if there was no grade IV neutropenia. Freyer and colleagues reported a response rate of $31 \%[31]$.

\section{The NAME trial}

The Name trial is an investigator-initiated, prospective, randomized Phase II, nonblinded multinational, multicenter study approved in Denmark and Norway. Women diagnosed with HER-2 negative, MBC ( $n=200)$ will be enrolled according to the study protocol.

\section{Background \& rationale for $\mathrm{mCHT}$ in patients with $\mathrm{MBC}$}

During the recent decade, we have seen an increasing interest in the concept of $\mathrm{mCHT}$ for MBC. Several Phase II trials involving compounds like 5-fluororacil, capecitabine, vinorelbine, cyclophosphamide and erlotinib have been published (Table 1) [32-37]. However, so far there are no clinical trials reported that used daily therapy with 
Table 1. Metronomic vinorelbine (Navelbine) in patients with metastatic breast cancer - selected studies.

\begin{tabular}{|c|c|c|c|c|c|}
\hline Study & Phase/clinical setting & Treatment arms & $\mathbf{n}$ & Main results & Ref. \\
\hline Addeo et al. & Phase II; first line & $\begin{array}{l}\text { VNB } 70 \mathrm{mg} / \mathrm{m}^{2} \mathrm{~d} 1,3 \text { and } 5 \text { ( } 1 \text { week } \\
\text { on } / 1 \text { week off) }\end{array}$ & 34 & $\begin{array}{l}\text { ORR: } 38 \%(28-48) \\
\text { CBR: } 68 \%(60.7-81.9) \\
\text { TTP: } 7.7 \text { months }(6.9-9.05)\end{array}$ & [32] \\
\hline De luliis et al. & Pretreated with several lines; Phase II & VNB $30 \mathrm{mg}$ q2d; contiuously & 32 & $\begin{array}{l}\text { ORR: } 68.7 \% \\
\text { CBR: } 78.1 \% \\
\text { TTP: } 9.2 \text { months }\end{array}$ & [37] \\
\hline Addeo et al. & $\begin{array}{l}\text { Second line and first line with brain } \\
\text { mets. }\end{array}$ & $\begin{array}{l}\text { TMZ } 75 \mathrm{mg} / \mathrm{m}^{2}+\text { WBRT } \\
\text { VNR } 70 \mathrm{mg} / \mathrm{m}^{2} \mathrm{~d} 1,3 \text { and } 5+\mathrm{TMZ} \\
75 \mathrm{mg} / \mathrm{m}^{2} \mathrm{~d} 1-21\end{array}$ & 32 & $\begin{array}{l}\text { ORR: } 52 \%(38-67) \\
\text { CBR: } 77 \%(62.7-88.9)\end{array}$ & [33] \\
\hline $\begin{array}{l}\text { Cazzaniga et al. } \\
\text { (VICTOR-1 trial) }\end{array}$ & First or second line; Phase I-II & $\begin{array}{l}\text { VNR } 40 \mathrm{mg} \mathrm{d} 1,3 \text { and } 5+\text { CAPE } \\
500 \mathrm{mg} \text { TID }\end{array}$ & 34 & CBR: $58.1 \%$ & [34] \\
\hline $\begin{array}{l}\text { Cazzaniga et al. } \\
\text { (VICTOR-2 trial) }\end{array}$ & First or second line; Phase I-II & $\begin{array}{l}\text { VNR } 40 \mathrm{mg} \mathrm{d} 1,3 \text { and } 5+\text { CAPE } \\
500 \mathrm{mg} \text { TID }\end{array}$ & 85 & $\begin{array}{l}\text { CBR: } 81 \% \text { (first line) } \\
\text { CBR } 73 \% \text { (second line) }\end{array}$ & [35] \\
\hline $\begin{array}{l}\text { Montagna et al. } \\
\text { VEX-trial }\end{array}$ & $\begin{array}{l}\text { Treatment-naive patients vs } \\
\text { pretreated }\end{array}$ & $\begin{array}{l}\text { VNR } 40 \mathrm{mg} \mathrm{d} 1,3 \text { and } 5+\text { CAPE } \\
500 \mathrm{mg} \text { TID }+ \text { CTX } 50 \mathrm{mg} / \mathrm{d}\end{array}$ & $\begin{array}{l}42 \text { vs } \\
46\end{array}$ & TTP: 26.5 vs 9.6 months & [36] \\
\hline
\end{tabular}

CAPE: Capecitabine; CBR: Clinical benefit rate; CTX: Cyclophosphamide; d: Day; ORR: Overall response rate; qxd: Every x day; TID: Three-times daily; TMZ: Temozolomide; TTP: Time to progression; VNR: Vinorelbine; WBRT: Whole-brain radiotherapy.

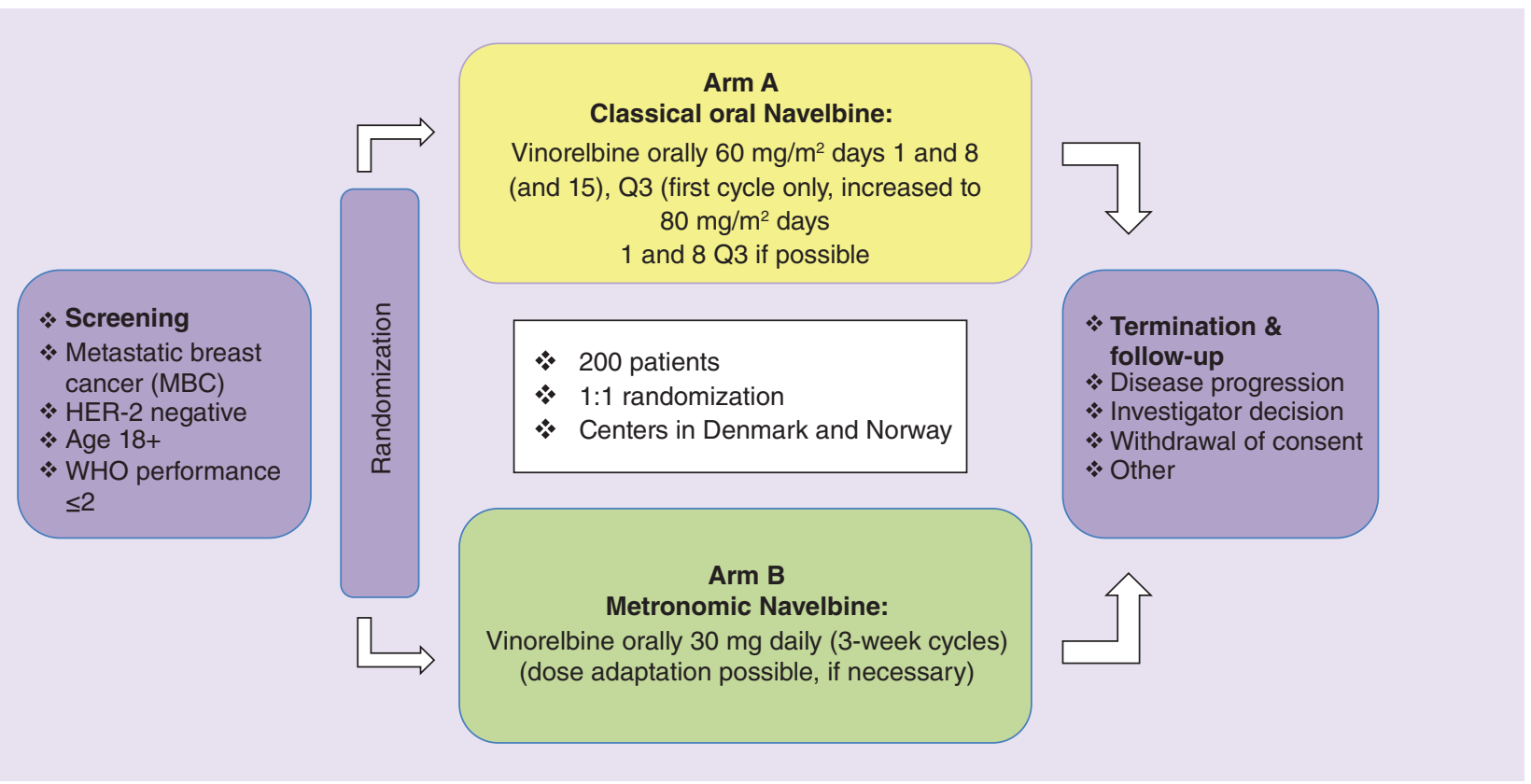

Figure 2. Study design - the NAME trial.

Q3: Every 3 weeks.

vinorelbine for MBC. In contrast, a Phase I trial with daily therapy of vinorelbine has been published for lung cancer patients by Gütz et al. [38]. In this dose escalation study, patients were treated daily with vinorelbine for 3 weeks followed by a 1-week break. The study included 27 patients from three German cancer centers. About $78 \%$ of the patients had stage IV disease with relapse and $93 \%$ had received prior chemotherapy. The median age of the study population was 65 years. Patients were treated with daily doses of vinorelbine between 20 and $50 \mathrm{mg}$. The investigators recommended a daily dose of $30 \mathrm{mg}$ which could be subsequently increased to $40 \mathrm{mg}$ daily for some patients [38]. No significant accumulation of vinorelbine was observed.

\section{Study design}

The NAME trial is a randomized, open label, multicenter, multinational, Phase II clinical trial (Figure 2). 
Box 1. General inclusion and exclusion criteria (NAME trial).

\section{Inclusion criteria}

- Women with histological confirmed metastatic breast cancer. The tumor cells should be tested HER-2 negative from the primary tumor or by biopsy of metastatic sites (measured with IHC 0-1 or IHC 2+ with consecutive, negative FISH or CISH)

- Expected life time of more than 12 weeks

- Age 18+

- WHO performance status $\leq 2$

- Patients, who, after oral and written information about the trial, agree to be included in the study (written informed consent)

- Patients who are suitable for vinorelbine therapy

- Patients with only one solitary metastatic lesion must have an cytological or histological confirmation of the diagnosis

- Negative pregnancy test (urine test)

Exclusion criteria

- Previous treatment with vinorelbine

- Parallel treatment with other anticancer therapies

- Patients with peripheral sensory neuropathy (> grade 2)

- Malabsorption syndromes or previous surgery with resection of stomach or small intestine (potentially affecting the absorption of vinorelbine)

- Difficulty with swallowing tablets

- Pregnant or breast-feeding women

- Women with childbearing potential who are not using adequate contraception

- Clinical symptoms of CNS-metastasis requiring large doses of steroids

- Decreased bone marrow function defined by WBC count $<3.0 \times 10^{9} / \mathrm{I}$ or neutrophil counts $<1.5 \times 10^{9} / \mathrm{I}$ or platelets $<75 \times 10^{9} / 1$

- Hepatic impairment defined by bilirubin $>1.5$-times UNL

- Renal impairment defined by serum-creatinine $>1.5$-times UNL

- Creatinine clearance $<50 \mathrm{ml} / \mathrm{min}$

- Other severe medical conditions, including serious heart disease, unstable diabetes mellitus, uncontrolled hypercalcemia, clinically active infections or organ transplanations

- Participation in other clinical trials with experimental therapy arms within the last 30 days

CISH: Chromogenic in situ hybridization; FISH: Fluorescence in situ hybridization; UNL: Upper normal limit.

\section{Primary, secondary or tertiary objectives}

Treatment will be given first or second line (chemotherapy). The primary objective is to evaluate and compare the disease control rate (complete response $[\mathrm{CR}]+$ partial response $[\mathrm{PR}]+$ stable disease $[\mathrm{SD}], \mathrm{SD}>3$ months) in the two arms. Secondary objectives are to compare the duration of disease control, time to progression, response rate (RR), duration of response (DR), overall survival (OS) and side effects for the two regimens. Evaluation of the global health status/quality of life (QoL), on the basis of the EORTC QOL C30 questionnaire will be performed. At last, a translational study to explore the potential of biomarkers during metronomic therapy is planned. The patients will be treated until disease progression or to unacceptable high toxicity, unless the patient wishes discontinuation of treatment for other reasons.

\section{Key eligibility criteria}

Patients with metastatic, HER-2-negative breast cancer, who experience progression of their disease and who are candidates for first- or second-line treatment with chemotherapy are eligible for this trial. Inclusion and exclusion criteria for the NAME trial are summarized in Box 1.

\section{Dose \& schedule of therapy}

Patients enrolled in the NAME trial are randomized to one of the two following treatment arms (see also Table 2 for more details concerning the drug doses used in the two study arms):

- Control arm (arm A), or Classical treatment: Navelbine orally: vinorelbine $\left(60 \mathrm{mg} / \mathrm{m}^{2}\right)$ on day 1 and day 8 (and day 15), every 3 weeks for the first cycle followed by $80 \mathrm{mg} / \mathrm{m}^{2}$ on day 1 and day 8 , every 3 weeks for the following cycles. 
Table 2. Standard doses of vinorelbine according to dose levels and body surface in arm A and B of the NAME trial.

\begin{tabular}{|c|c|c|c|c|c|c|c|}
\hline \multicolumn{8}{|c|}{ Arm A } \\
\hline \multicolumn{4}{|c|}{ Vinorelbine $60 \mathrm{mg} / \mathrm{m} 2$ (Day $1+8 \mathrm{q} 3$ ) } & \multicolumn{4}{|c|}{ Vinorelbine $80 \mathrm{mg} / \mathrm{m}^{2}$ (Day $1+8 \mathrm{q} 3$ ) } \\
\hline \multicolumn{2}{|c|}{ Body surface } & \multicolumn{2}{|l|}{ Dose level } & \multicolumn{2}{|c|}{ Body surface } & \multicolumn{2}{|l|}{ Dose level } \\
\hline $\mathrm{m}^{2}$ & 0 & $-1(75 \%$ dose $)$ & $-2(50 \%$ dose $)$ & $\mathrm{m}^{2}$ & 0 & -1 (75\% dose) & -2 (50\% dose) \\
\hline $1.55-1.71 \mathrm{~m}^{2}$ & $100 \mathrm{mg}$ & $80 \mathrm{mg}$ & $50 \mathrm{mg}$ & $1.55-1.71 \mathrm{~m}^{2}$ & $130 \mathrm{mg}$ & $100 \mathrm{mg}$ & $60 \mathrm{mg}$ \\
\hline $1.72-1.90 \mathrm{~m}^{2}$ & $110 \mathrm{mg}$ & $80 \mathrm{mg}$ & $50 \mathrm{mg}$ & $1.72-1.90 \mathrm{~m}^{2}$ & $140 \mathrm{mg}$ & $110 \mathrm{mg}$ & $70 \mathrm{mg}$ \\
\hline \multicolumn{8}{|c|}{ Dose level } \\
\hline 0 & -1 & -2 & & & & & \\
\hline $30 \mathrm{mg}$ & $20 \mathrm{mg}$ & $20 \mathrm{mg}$ & & & & & \\
\hline Daily & Daily & Every other day & & & & & \\
\hline
\end{tabular}

- Experimental arm (arm B), or Metronomic treatment: vinorelbine orally: with 3-week cycles of daily doses of $30 \mathrm{mg}$ (patients with body surface $\leq 1.54 \mathrm{~m}^{2}$ or $\geq 65$ years of age start on $20 \mathrm{mg}$ vinorelbine daily).

\section{Efficacy evaluations}

The response of breast cancer patients with metastatic disease during vinorelbine therapy in the two arms of the NAME trial will be evaluated by CT scans of the chest and abdomen according to the established RECIST criteria. Additional MRI-scans and x-rays may be performed whenever clinical useful. At baseline, measurable and evaluable metastases must be documented by identification of at least one bidirectionally measurable lesion. Solitary lesions must be verified by cytology/histology. All tumor measurements will be performed approximately every 3 months in accordance to standard procedures in oncology in both Denmark and Norway.

\section{Safety evaluations}

Adverse events (AE) and laboratory abnormalities will be monitored throughout the entire study. All AEs will be evaluated using the National Cancer Institute (NCI), Common Terminology Criteria for Adverse Events (CTCAE) V.4.0 on a scale of five grades and detailed in the electronic case report form (eCRF) forms. AEs not listed in the CTCAE must be classified accordingly to five grades (mild, moderate, severe, life-threatening and death) as described in the study protocol. Symptoms clearly related to the progression of the underlying malignancy will not be reported as serious adverse events (SAEs). Hospitalization, solely due to the progression of breast cancer should not be reported as an SAE. However, if in doubt, symptoms will be reported by the responsible oncologists as SAEs. Due to the severity of the primary diagnosis advanced breast cancer, a number of events may be excluded from SAE reporting like hospitalization due to bone marrow depression, fever or nausea and vomiting. These side effects will, however, always be reported in the eCRF system. After completion of the study treatment period, the responsible physician shall follow-up all reported AEs and SAEs according to the procedures defined in the NAME protocol. Local laboratories will be used for all biochemical testing during the trial. All abnormalities will be reported in the eCRF system as defined in the study protocol.

\section{Statistical analysis}

The clinical efficacy of each given therapy during the trial will be evaluated after 9 weeks on therapy (three series of classical vinorelbine). RECIST 1.1 criteria will be used to evaluate all effects [39]. All areas of metastasis are to be monitored and the lesions will be categorized as either measureable or nonmeasureable. The overall response rate will also be evaluated using RECIST 1.1. Clinical chemistry alone may not be used to define response to therapy. Descriptive statistics will be used to summarize subject characteristics, AEs and duration of responses, etc. The response rate and its $95 \% \mathrm{CI}$ will be reported in the planned publication.

\section{Conclusion}

Vinorelbine (Navelbine) is a well-established vinca alkaloid for the treatment of MBC. The drug is usually given either orally or intravenously on days 1 and 8 every 3 weeks. The NAME trial aims to investigate the potential efficacy of administering vinorelbine according to a metronomic dose schedule, meaning small doses administered 
every single day. Our hypothesis is that metronomic therapy with vinorelbine has the potential to be at least as effective as classical vinorelbine, while with less associated side effects.

\section{Executive summary}

\section{Background}

- Breast cancer is one of the most common cancer types among women in the world. Metastatic breast cancer is currently incurable and available chemotherapy is only prolonging survival at a modest level.

- Metronomic chemotherapy is a new approach aiming at stabilization of the advanced breast cancer disease while decreasing side effects compared with traditional administration.

\section{Vinorelbine/Navelbine}

- Vinorelbine (Navelbine) is a well-established member of the vinca alkaloids, blocking cell division in the $\mathrm{G} 2 / \mathrm{M}$-phase of the cell cycle by inhibiting the assembly of microtubules necessary for the cell division. The drug is established both as intravenous therapy and oral therapy mostly for lung cancer and breast cancer.

The NAME trial

- The NAME trial is an investigator-initiated, multinational, prospective, randomized, open-label, Phase II trial running in Denmark and Norway.

- A total of 200 women with HER-2 negative, metastatic breast cancer will be enrolled.

- The patients are randomized to two treatment arms:

- Arm A: first cycle: Navelbine $60 \mathrm{mg} / \mathrm{m}^{2}$ p.o. on days 1 and 8 (15) every 3 weeks; all following cycles: Navelbine $80 \mathrm{mg} / \mathrm{m}^{2}$ p.o. on days 1 and 8 every 3 weeks.

- Arm B: 30 mg Navelbine given orally and daily; (dose adaptation may be performed according to protocol).

- Treatment will be given until disease progression has been confirmed using RECIST criteria or until the investigator terminates the treatment for other reasons according to the protocol.

- The trial has been approved by all national authorities in both Denmark and Norway.

Conclusion

- The NAME trial will clarify the role of metronomic chemotherapy with Navelbine in patients with metastatic breast cancer.

\section{Acknowledgments}

The authors wish to thank JC Noone for a careful revision of the English language used in this article.

\section{Clinical trial identification}

EUDRACT no: 2016-002165-63. Health Board no: 2017040059. Approved by the Danish Research Ethics Committee and Data Protection Agency June 2017. The trial was also approved in Norway by the regional ethics committee (2017/1829) and the National Medical Agency of Norway (SLV 18/06310-16) in 2018.

Financial \& competing interests disclosure

The study is an investigator-initiated study, but financially supported by the pharmaceutical company Pierre Fabre. J Geisler received consulting fees from Novartis Pharmaceuticals, Pfizer Inc., AstraZeneca, Merck, MSD, Roche, BMS and Pierre Fabre. The authors have no other relevant affiliations or financial involvement with any organization or entity with a financial interest in or financial conflict with the subject matter or materials discussed in the manuscript apart from those disclosed.

No writing assistance was utilized in the production of this manuscript.

Open access

This work is licensed under the Attribution-NonCommercial-NoDerivatives 4.0 Unported License. To view a copy of this license, visit http://creativecommons.org/licenses/by-nc-nd/4.0/

\section{References}

Papers of special note have been highlighted as: $\bullet$ of interest; $\bullet \bullet$ of considerable interest

1. Hortobagyi GN. Future directions for vinorelbine (Navelbine). Semin. Oncol. 22(2 Suppl. 5), 80-86 (1995).

2. Fumoleau P, Delozier T, Extra JM, Canobbio L, Delgado FM, Hurteloup P. Vinorelbine (Navelbine) in the treatment of breast cancer: the European experience. Semin. Oncol. 22(2 Suppl. 5), 22-28 (1995).

3. Gralla R, Harper P, Johnson S, Delgado FM. Vinorelbine (Navelbine) in the treatment of non-small-cell lung cancer: studies with single-agent therapy and in combination with cisplatin. Ann. Oncol. 10(Suppl. 5), S41-S45 (1999). 
4. Hanahan D, Bergers G, Bergsland E. Less is more, regularly: metronomic dosing of cytotoxic drugs can target tumor angiogenesis in mice. J. Clin. Invest. 105(8), 1045-1047 (2000).

-. Important publication covering the influence of metronomic chemotherapy (mCHT) on angiogenesis.

5. Briasoulis E, Pappas P, Puozzo C et al. Dose-ranging study of metronomic oral vinorelbine in patients with advanced refractory cancer. Clin. Cancer Res. 15(20), 6454-6461 (2009).

-• Pivotal clinical evidence regarding the potential of metronomic vinorelbine in humans.

6. Scharovsky OG, Mainetti LE, Rozados VR. Metronomic chemotherapy: changing the paradigm that more is better. Curr. Oncol. 16(2), 7-15 (2009).

7. Sharma R. Breast cancer incidence, mortality and mortality-to-incidence ratio (MIR) are associated with human development, 1990-2016: evidence from Global Burden of Disease Study 2016. Breast Cancer 26(4), 428-445 (2019).

8. Hortobagyi GN. Progress in systemic chemotherapy of primary breast cancer: an overview. J. Natl Cancer Inst. Monogr. (30), 72-79 (2001).

9. Andreopoulou E, Sparano JA. Chemotherapy in patients with anthracycline- and taxane-pretreated metastatic breast cancer: an overview. Curr. Breast Cancer Rep. 5(1), 42-50 (2013).

10. Kaufman PA, Awada A, Twelves C et al. Phase III open-label randomized study of eribulin mesylate versus capecitabine in patients with locally advanced or metastatic breast cancer previously treated with an anthracycline and a taxane. J. Clin. Oncol. 33(6), 594-601 (2015).

11. Twelves C, Cortes J, Vahdat LT, Wanders J, Akerele C, Kaufman PA. Phase III trials of eribulin mesylate (E7389) in extensively pretreated patients with locally recurrent or metastatic breast cancer. Clin. Breast Cancer 10(2), 160-163 (2010).

12. Johnson SA, Harper P, Hortobagyi GN, Pouillart P. Vinorelbine: an overview. Cancer Treat. Rev. 22(2), 127-142 (1996).

13. Pietras K, Hanahan D. A multitargeted, metronomic, and maximum-tolerated dose "chemo-switch" regimen is antiangiogenic, producing objective responses and survival benefit in a mouse model of cancer. J. Clin. Oncol. 23(5), 939-952 (2005).

14. Munzone E, Colleoni M. Clinical overview of metronomic chemotherapy in breast cancer. Nat. Rev. Clin. Oncol. 12(11), 631-644 (2015).

-• Recommended overview paper summarizing the effects of $\mathrm{mCHT}$ in breast cancer patients.

15. Alagizy HA, Shehata MA, Hashem TA, Abdelaziz KK, Swiha MM. Metronomic capecitabine as extended adjuvant chemotherapy in women with triple negative breast cancer. Hematol. Oncol. Stem Cell Ther. 8(1), 22-27 (2015).

16. Masuda N, Higaki K, Takano T et al. A Phase II study of metronomic paclitaxel/cyclophosphamide/capecitabine followed by 5-fluorouracil/epirubicin/cyclophosphamide as preoperative chemotherapy for triple-negative or low hormone receptor expressing/HER2-negative primary breast cancer. Cancer Chemother. Pharmacol. 74(2), 229-238 (2014).

17. Saridaki Z, Malamos N, Kourakos $\mathrm{P}$ et al. A Phase I trial of oral metronomic vinorelbine plus capecitabine in patients with metastatic breast cancer. Cancer Chemother. Pharmacol. 69(1), 35-42 (2012).

18. Rozados VR, Mainetti LE, Rico MJ, Zacarias Fluck MF, Matar P, Scharovsky OG. The immune response and the therapeutic effect of metronomic chemotherapy with cyclophosphamide. Oncol. Res. 18(11-12), 601-605 (2010).

19. Man S, Bocci G, Francia G et al. Antitumor effects in mice of low-dose (metronomic) cyclophosphamide administered continuously through the drinking water. Cancer Res. 62(10), 2731-2735 (2002).

- Important basic research using cyclophosphamide as mCHT agent.

20. Mathe G, Reizenstein P. Phase I pharmacologic study of a new Vinca alkaloid: Navelbine. Cancer Lett. 27(3), 285-293 (1985).

21. Langkjer ST, Ejlertsen B, Mouridsen H et al. Vinorelbine as first-line or second-line therapy for advanced breast cancer: a Phase I-II trial by the Danish Breast Cancer Co-operative Group. Acta Oncol. 47(4), 735-739 (2008).

22. Canobbio L, Boccardo F, Pastorino G et al. Phase-II study of Navelbine in advanced breast cancer. Semin. Oncol. 16(2 Suppl. 4), 33-36 (1989).

23. Fumoleau P, Delgado FM, Delozier T et al. Phase II trial of weekly intravenous vinorelbine in first-line advanced breast cancer chemotherapy. J. Clin. Oncol. 11(7), 1245-1252 (1993).

24. Garcia-Conde J, Lluch A, Martin M et al. Phase II trial of weekly iv vinorelbine in first-line advanced breast cancer chemotherapy. Ann. Oncol. 5(9), 854-857 (1994).

25. Bruno S, Puerto VL, Mickiewicz E et al. Phase II trial of weekly i.v. vinorelbine as a single agent in first-line advanced breast cancer chemotherapy. The Latin-American experience. Am. J. Clin. Oncol. 18(5), 392-396 (1995).

26. Terenziani M, Demicheli R, Brambilla C et al. Vinorelbine: an active, non cross-resistant drug in advanced breast cancer. Results from a Phase II study. Breast Cancer Res. Treat. 39(3), 285-291 (1996).

27. Ejlertsen B, Mouridsen HT, Langkjer ST et al. Phase III study of intravenous vinorelbine in combination with epirubicin versus epirubicin alone in patients with advanced breast cancer: a Scandinavian Breast Group Trial (SBG9403). J. Clin. Oncol. 22(12), 2313-2320 (2004).

- Pivotal clinical trial demontrating superiority of the combination vinorelbine/epirubicin compared with vinorelbine monotherapy in breast cancer patients. 
28. Andersson M, Lidbrink E, Bjerre K et al. Phase III randomized study comparing docetaxel plus trastuzumab with vinorelbine plus trastuzumab as first-line therapy of metastatic or locally advanced human epidermal growth factor receptor 2-positive breast cancer: the HERNATA study. J. Clin. Oncol. 29(3), 264-271 (2011).

-• Important clinical trial establishing Navelbine as a potent partner for trastuzumab in HER-2 positive metastatic breast cancer.

29. Marty M, Fumoleau P, Adenis A et al. Oral vinorelbine pharmacokinetics and absolute bioavailability study in patients with solid tumors. Ann. Oncol. 12(11), 1643-1649 (2001).

30. Jassem J, Ramlau R, Karnicka-Mlodkowska $\mathrm{H}$ et al. A multicenter randomized Phase II study of oral vs. intravenous vinorelbine in advanced non-small-cell lung cancer patients. Ann. Oncol. 12(10), 1375-1381 (2001).

31. Freyer G, Delozier T, Lichinister M et al. Phase II study of oral vinorelbine in first-line advanced breast cancer chemotherapy. J. Clin. Oncol. 21(1), 35-40 (2003).

32. Addeo R, Sgambato A, Cennamo G et al. Low-dose metronomic oral administration of vinorelbine in the first-line treatment of elderly patients with metastatic breast cancer. Clin. Breast Cancer 10(4), 301-306 (2010).

33. Addeo R, Sperlongano P, Montella L et al. Protracted low dose of oral vinorelbine and temozolomide with whole-brain radiotherapy in the treatment for breast cancer patients with brain metastases. Cancer Chemother. Pharmacol. 70(4), 603-609 (2012).

34. Cazzaniga ME, Torri V, Villa F et al. Efficacy and safety of the all-oral schedule of metronomic vinorelbine and capecitabine in locally advanced or metastatic breast cancer patients: the Phase I-II VICTOR-1 study. Int. J. Breast Cancer 2014, 769790 1-7 (2014).

35. Cazzaniga ME, Cortesi L, Ferzi A et al. Metronomic chemotherapy with oral vinorelbine (mVNR) and capecitabine (mCAPE) in advanced HER2-negative breast cancer patients: is it a way to optimize disease control? Final results of the VICTOR-2 study. Breast Cancer Res. Treat. 160(3), 501-509 (2016).

36. Montagna E, Palazzo A, Maisonneuve P et al. Safety and efficacy study of metronomic vinorelbine, cyclophosphamide plus capecitabine in metastatic breast cancer: a Phase II trial. Cancer Lett. 400, 276-281 (2017).

37. De Iuliis F, Salerno G, Taglieri L, Lanza R, Scarpa S. On and off metronomic oral vinorelbine in elderly women with advanced breast cancer. Tumori 101(1), 30-35 (2015).

38. Guetz S, Tufman A, Von Pawel J et al. Metronomic treatment of advanced non-small-cell lung cancer with daily oral vinorelbine - a Phase I trial. Onco. Targets Ther. 10, 1081-1089 (2017).

39. Eisenhauer EA, Therasse P, Bogaerts J et al. New response evaluation criteria in solid tumors: revised RECIST guideline (version 1.1). Eur. J. Cancer 45(2), 228-247 (2009). 
